\title{
Genetic diversity and population structure of Mongolian regional horses with 14 microsatellite markers
}

\author{
Jihye Yun ${ }^{1}$, Baatartsogt Oyungerel ${ }^{2}$, and Hong Sik Kong ${ }^{1,3,4, *}$
}

\author{
* Corresponding Author: Hong sik Kong \\ Tel: +82-31-670-5334, \\ Fax: +82-504-842-4615, \\ E-mail: kebinkhs@hknu.ac.kr
}

${ }^{1}$ Department of Applied Biotechnology, The Graduate School of Hankyong National University, Anseong 17579, Korea

2 School of Animal Science and

Biotechnology, Mongolian University of Life Sciences, Zaisan 17024, Ulaanbaatar,

Mongolia

${ }^{3}$ Genomic Informatics Center, Hankyong National University, Anseong 17579, Korea

${ }^{4}$ Gyeonggi Regional Research Center, Hankyong National University, Anseong 17579 , Korea

ORCID

Jihye Yun

https://orcid.org/0000-0002-4558-2337 Baatartsogt Oyungerel

https://orcid.org/0000-0002-5949-9841

Hong Sik Kong

https://orcid.org/0000-0003-1144-016X

Submitted Nov 10, 2021; Revised Jan 10, 2022; Accepted Feb 16, 2022
Objective: This study aimed to identify the genetic diversity and population structure of Mongolian horse populations according to the province of residence (Khentii, KTP; Uvs, USP; Omnogovi and Dundgovi, GOP; Khovsgol, KGP) using 14 microsatellite (MS) markers. Methods: A total of 269 whole blood samples were obtained from the four populations (KTP, USP, GOP, KGP) geographically distinct provinces. Multiplex polymerase chain reaction (PCR) was conducted using $14 \mathrm{MS}$ markers (AHT4, ASB2, ASB17, ASB23, CA425, HMS1, HMS2, HMS3, HMS6, HMS7, HTG4, HTG6, HTG7, and VHL20), as recommended by the International Society for Animal Genetics. Capillary electrophoresis was conducted using the amplified PCR products, alleles were determined. Alleles were used for statistical analysis of genetic variability, Neis DA genetic distance, principal coordinate analysis (PCoA), factorial corresponding analysis (FCA), and population structure.

Results: On average, the number of alleles, expected heterozygosity $\left(\mathrm{H}_{\mathrm{Exp}}\right)$, observed heterozygosity $\left(\mathrm{H}_{\mathrm{Obs}}\right)$, and polymorphic information content among all populations were 11.43 , $0.772,0.757$, and 0.737 , respectively. In the PCoA and FCA, GOP, and KGP were genetically distinct from other populations, and the KTP and USP showed a close relationship. The two clusters identified using Nei's DA genetic distance analysis and population structure highlighted the presence of structurally clear genetic separation.

Conclusion: Overall, the results of this study suggest that genetic diversity between KTP and USP was low, and that between GOP and KGP was high. It is thought that these results will help in the effective preservation and improvement of Mongolian horses through genetic diversity analysis and phylogenetic relationships.

Keywords: Genetic Diversity; Horse; Microsatellites; Mongolia; Relationships; Structure

\section{INTRODUCTION}

Horses (Equus caballus) have been domesticated in steppes and have played an important role in the development of several civilizations. In Mongolia, horses are one of the five livestock species, and according to [1], as of 2020, of the approximately 67.07 million livestock in Mongolia, 4.09 million are horses. The Mongolian horse is one of the most ancient breeds in the world and has adapted to Mongolias climate and environment. The Mongolians were able to move easily using horses to find better grasslands, increase the number of livestock, and expand foreign relations. Therefore, Mongolian horses occupy an important place in Mongolia's nomadic lives.

The ancient wild Mongolian horse is known as Przewalskii [2,3]. Though the ancient Mongolian horse may have been the ancestor of several modern horse breeds, the protection and management of Mongolian horse's genetic resources is still insufficient. As the importance of livestock genetic resources increases worldwide, various studies are being conducted on the molecular genetic properties of genetic resources in order to 
preserve their value. Studies on genetic diversity are essential for the management of genetic resources through genetic characteristic analysis, breeding, and discovery of useful traits.

Microsatellites (MS) are used as molecular markers for genetic diversity analysis and breeding programs $[4,5]$. These molecular markers can be used to obtain information on the phylogenetic relationships or genetic variation. Microsatellite markers were first characterized in horses by Ellegren et al [6], Marklund et al [7]. These have since been used extensively to investigate the genetic diversity and breed characteristics of horse populations. As some horse breeds were domesticated in the steppes of Mongolia, it was predicted that there would be a high genetic diversity [8]. However, genetic analysis using MS markers is yet to be conducted among Mongolian horses. To study livestock genetic resources in Mongolia, it is necessary to analyze the genetic diversity and genetic relationship between Mongolian horse populations using an efficient MS marker.

In Mongolia, various breeds of horses inhabit the climate and topographical characteristics of each province. According to Wright [9] and Ganbold et al [10], Mongolian horses mainly inhabit steppes and dry areas such as Gobi. The appearance of Mongolian horses varies greatly depending on their habitat. Genetic characteristics also appear to be different. Khentii Province is a grassland region located in the eastern part of Mongolia, where various plants grow naturally. The Uvs province is located in the west of Mongolia, and the Omnogovi and Dundgovi provinces comprise the steppes in southern Mongolia. The Khovsgol province is a pasture located in northern Mongolia and has a cold climate.

As such, Mongolian horses have different traits depending on the province where they live, but the genetic diversity and correlations using MS markers have not yet been verified.
Therefore, this study aimed to identify the genetic characteristics of Mongolian horses according to the province of residence using $14 \mathrm{MS}$ markers published by the International Society of Animal Genetics (ISAG). We analyzed the genetic relationships and genetic diversity of horses raised in each of the five provinces (Khentii, Uvs, Omnogovi, Dundgovi, and Khovsgol) in Mongolia, which were divided into four populations. Genetic diversity analysis is expected to help in the effective protection and management of Mongolian horse genetic resources. In addition, the genetic structure and phylogenetic relationships of the Mongolian horse populations were also identified, and can be used as basic data for research on genetic resources of not only horses but also other livestock in Mongolia.

\section{MATERIAL AND METHODS}

\section{Genomic DNA extraction}

The experimental methods were approved by the Hankyong National University Animal Ethics Committee, Anseong, Republic of Korea (No.2021-1). A total of 269 whole blood samples were obtained from the four populations of the five geographically distinct provinces (Table 1, Figure 1). Sampling sites included i) East Mongolia Khentii Province (KTP, $n=53$ ); ii) West Mongolia Uvs Province (USP, $n=43$ );

Table 1. Sample information in this study

\begin{tabular}{lcc}
\hline Province types & Sample size & Collection location \\
\hline Khentii province (KTP) & 53 & East Mongolia \\
Uvs province (USP) & 43 & West Mongolia \\
Omnogovi, Dundgovi province & 133 & Southern Mongolia \\
$\quad($ GOP) & & \\
Khovsgol province (KGP) & 40 & Northern Mongolia \\
Total & 269 & - \\
\hline
\end{tabular}

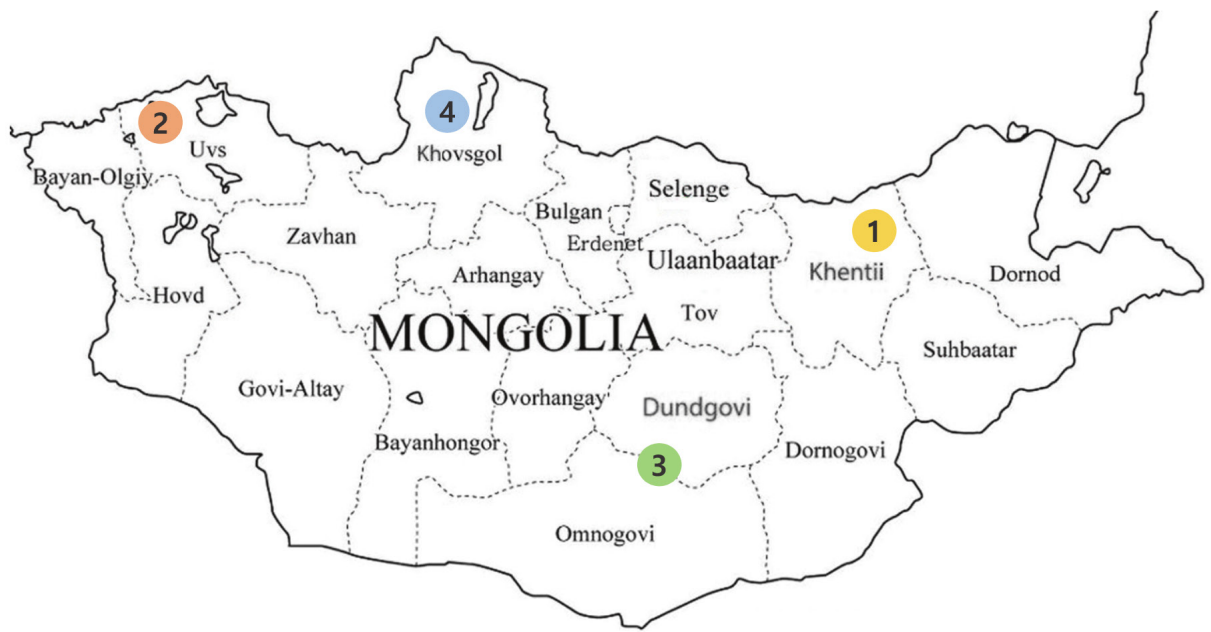

Figure 1. Four Mongolian horse populations from the five provinces of Mongolia. 1. Khentii province (KTP); 2. Uvs province (USP); 3. Omnogovi and Dundgovi province (GOP); and 4. Khovsgol province (KGP). 
iii) Southern Mongolia Omnogovi and Dundgovi provinces (GOP, $\mathrm{n}=133$ ); and iv) Northern Mongolia Khovsgol province (KGP, $n=40$ ). Genomic DNA was extracted from blood samples using the methods described for QuickGene 810 (Kurabo, Osaka, Japan). The concentration and purity of the extracted genomic DNA were evaluated using an ND-1000 UV-Vis spectrophotometer (NanoDrop Technologies, Wilmington, DE, USA).

\section{Information on the microsatellite markers}

The genetic diversity of Mongolian horse populations was identified using 14 MS markers (AHT4, ASB2, ASB17, ASB23, CA425, HMS1, HMS2, HMS3, HMS6, HMS7, HTG4, HTG6, HTG7, and VHL20), as recommended by the ISAG.

\section{Composition of multiplex-polymerase chain reaction} and the polymerase chain reaction procedure

Multiplex polymerase chain reaction (PCR) was conducted using the Equine Genotypes Panel 1.1 Kit (Thermo Fisher Scientific, Waltham, MA, USA) for genotyping of the 14 MS markers. Following the manufacturer's instructions, the reaction mixture was prepared using $2 \mu \mathrm{L}$ genomic DNA (1.0 ng $/ \mu \mathrm{L}), 9 \mu \mathrm{L}$ master mix, and $9 \mu \mathrm{L}$ primer mix, obtaining a total volume of $20 \mu \mathrm{L}$. The PCR was conducted using a GeneAmp PCR system 9700 (Applied Biosystems, Waltham, MA, USA). The PCR amplification was conducted using the following conditions: pre-denaturation at $98^{\circ} \mathrm{C}$ for 3 min followed by 30 cycles of $15 \mathrm{~s}$ at $98^{\circ} \mathrm{C}, 75 \mathrm{~s}$ at $60^{\circ} \mathrm{C}$, and 1 cycle of $30 \mathrm{~s}$ at $72^{\circ} \mathrm{C}$. The final extension step was performed at $72^{\circ} \mathrm{C}$ for $5 \mathrm{~min}$ and the mixture was cooled to $4^{\circ} \mathrm{C}$.

\section{Genotyping of microsatellite}

Using Hi-Di formamide, amplified PCR products were diluted 50 to 100 times, and the diluted PCR products $(1 \mu \mathrm{L})$ were further diluted using a mixture of $9 \mu \mathrm{L}$ Hi-Di formamide and GeneScan 500LIZ size standard (Applied Biosystems, USA). After denaturation at $95^{\circ} \mathrm{C}$ for $3 \mathrm{~min}$, capillary electrophoresis was conducted using an ABI 3730xl Genetic Analyzer (Applied Biosystems, USA). The size of each MS marker was determined using GeneMapper ver 5.0 (Applied Biosystems, USA). The determined alleles were collated using Microsoft Excel (Microsoft, Redmond, WA, USA) and used for statistical analysis.

\section{Statistical analysis of data}

The MS Toolkit software [11] was used to calculate the number of alleles, expected and observed heterozygosity $\left(\mathrm{H}_{\mathrm{Exp}}\right.$ and $\mathrm{H}_{\mathrm{Obs}}$, respectively), and polymorphism information content (PIC) values. To identify genetic correlations between populations, allele frequencies for each marker were confirmed using GenAlEx 6.4 [12] and Genetix software [13]. For this, principal coordinate analysis ( $\mathrm{PCoA})$ was conducted using GenAlEx 6.4 to display the two-dimensional coordinates. Factorial component analysis (FCA) was conducted using Genetix to display the three-dimensional coordinates. The genetic distance between populations was calculated based on allele frequencies according to Nei's DA genetic distance [14] using POPTREE2 [15]. A phylogenetic tree was estimated from the genetic distances using the neighbor-joining method [16] with the DISPAN program [17]. Population structure $[18,19]$ was used to estimate the uniformity of the population, and the $\mathrm{K}$ value was set to estimate the number of distinct populations $(\Delta \mathrm{K})$. To calculate the average estimate and standard deviation of each $\mathrm{K}$ value, the length of the burn-in period and the number of Markov chain Monte Carlo (MCMC) repetitions after the burn-in frequency were set, and the optimal $\mathrm{K}$ value and genetic uniformity for each cluster were calculated The results were applied to the Structure harvester [20] using the Evanno method [21].

\section{RESULTS}

\section{Microsatellite polymorphism}

The number of alleles, $\mathrm{H}_{\text {Exp }}, \mathrm{H}_{\text {Obs }}$, and PIC values for the Mongolian horse populations are summarized (Table 2). A total of 160 different alleles were detected, ranging from 6 (HTG7) to 22 (ASB2). $\mathrm{H}_{\text {Exp }}$ and $\mathrm{H}_{\text {Obs }}$ ranged from 0.572 (HTG4) to 0.885 (ASB17) and 0.561 (HTG4) to 0.868 (ASB17), with mean values of 0.772 and 0.757 , respectively. PIC values ranged from 0.535 (HTG4) to 0.866 (ASB17), with a mean value of 0.737 . Except for the HTG4 marker $\left(\mathrm{H}_{\text {Exp }}=0.572\right.$, $\mathrm{PIC}=0.535)$ used in this study, all other MS markers were considered to be highly useful in analyzing polymorphism

Table 2. Characterization of the 14 MS marker loci analyzed in 269 Mongolian horses

\begin{tabular}{lcccc}
\hline Marker & No of allele & $\mathbf{H}_{\text {Exp }}$ & $\mathbf{H}_{\text {obs }}$ & PIC \\
\hline AHT4 & 11 & 0.807 & 0.754 & 0.774 \\
ASB17 & 20 & 0.885 & 0.868 & 0.866 \\
ASB2 & 22 & 0.859 & 0.816 & 0.834 \\
ASB23 & 15 & 0.822 & 0.838 & 0.794 \\
CA425 & 12 & 0.798 & 0.786 & 0.764 \\
HMS1 & 7 & 0.688 & 0.664 & 0.632 \\
HMS2 & 12 & 0.796 & 0.825 & 0.758 \\
HMS3 & 10 & 0.805 & 0.723 & 0.772 \\
HMS6 & 8 & 0.799 & 0.810 & 0.762 \\
HMS7 & 8 & 0.721 & 0.718 & 0.681 \\
HTG4 & 7 & 0.572 & 0.561 & 0.535 \\
HTG6 & 11 & 0.712 & 0.642 & 0.676 \\
HTG7 & 6 & 0.716 & 0.748 & 0.660 \\
VHL20 & 11 & 0.835 & 0.839 & 0.804 \\
Mean & 11.43 & 0.772 & 0.757 & 0.737 \\
\hline
\end{tabular}

MS, microsatellite; $H_{\text {Exp }}$ expected heterozygosity frequency; $H_{\text {obs }}$ observed heterozygosity frequency; PIC, polymorphism information content. 
of Mongolian horse. MS markers were previously used to assess the genotypic diversity of heterozygosity and PIC value during animal breed selection. According to Botstein et al [22], polymorphisms of MS markers are determined using the following criteria: if the sum of $\mathrm{H}_{\mathrm{Exp}}$ is $\geq 0.6$ and PIC is $\geq 0.5$, then the marker is determined to be highly polymorphic. The heterozygosity $\left(\mathrm{H}_{\mathrm{Exp}}\right.$ and $\left.\mathrm{H}_{\mathrm{Obs}}\right)$ and PIC values with respect to the four Mongolian horse populations are summarized (Table 3 ). Among the provinces, the values for mean number of alleles (MNA), $\mathrm{H}_{\text {Exp }}, \mathrm{H}_{\mathrm{Obs}}$, and PIC were highest for KTP horses $(8.57,0.787,0.789$, and 0.751 , respectively) and lowest for KGP populations (7.07, $0.751,0.738$, and 0.706 , respectively).

\section{Genetic distance and phylogenetic analysis}

The genetic divergences among the four Mongolian horse populations based on allele frequencies were calculated according to Nei's DA genetic distance [16]. The phylogenetic relationships among these Mongolian horse populations were determined using the neighbor-joining tree (Figure 2). Grouping values were determined by 1,000 repetitive "bootstrap" tests to determine the reliability of the neighbor-joining tree and were specified at the branching points of the tree. The smaller the estimated genetic distance is, the closer each population is genetically. In Nei's DA genetic distance, the KTP and USP populations were the closest $(\mathrm{DA}=0.0535)$, and the largest difference was calculated for the GOP and KGP populations $(\mathrm{DA}=0.1797)($ Supplementary Table $\mathrm{S} 1)$. In the phylogenetic tree, the Mongolian horse populations was mainly divided into two clusters. The KTP and GOP populations formed the first cluster, and the KGP population formed the second cluster. The USP breed was located between the two clusters. The division of the populations into two distinct clusters highlighted the presence of clear genetic separation between each province.

\section{Principal coordinates analysis and factorial component analysis}

As the phylogenetic tree may not take into account the effects of admixture among the four populations, we conducted PCoA and FCA, using allele frequencies of the 14 MS markers, as an alternative approach to understand the genetic relationships among populations. The PCoA contributed to $100 \%$ of
Table 3. The statistical analysis of MNA, heterozygosity, and PIC using the $14 \mathrm{MS}$ markers in each province

\begin{tabular}{lcccc}
\hline Province types & MNA & $\mathbf{H}_{\text {Exp }}$ & $\mathbf{H}_{\text {obs }}$ & PIC \\
\hline Khentii province (KTP) & 8.57 & 0.787 & 0.789 & 0.751 \\
Uvs province (USP) & 9.07 & 0.779 & 0.756 & 0.744 \\
Omnogovi, Dundgovi province & 10.21 & 0.774 & 0.744 & 0.746 \\
$\quad$ GOP) & & & & \\
Khovsgol province (KGP) & 7.07 & 0.751 & 0.738 & 0.706 \\
Mean & 8.73 & 0.773 & 0.757 & 0.737 \\
\hline
\end{tabular}

MNA, mean number of alleles; PIC, polymorphism information content; MS, microsatellite; $H_{\text {Exp }}$, expected heterozygosity frequency; $H_{o b s}$ observed heterozygosity frequency.

the variation, including the third ingredient. The first three principal coordinates represented $60.13 \%, 29.75 \%$, and $10.12 \%$ of the total variation, respectively. The KGP and GOP populations were distinct from the other populations (Figure 3). In contrast, the KTP and USP populations were located between the closest genetic distances. The FCA analysis revealed that the three dimensions contributed to a total of 100 with Axis 1 (56.08), Axis 2 (29.86), and Axis 3 (14.06). The KTP and GOP populations were genetically differentiated from other populations and showed a close relationship among certain populations, including KTP and USP (Figure 4). Thus, results of the PCoA analysis were consistent with those of the FCA.

\section{Uniformity of horse population}

A Bayesian clustering method and population structure were used for clustering algorithms of multi-locus genotypes to identify the population structure and pattern of admixture within the populations. Population structure was used to estimate the number of groups that were classified by the group surveyed. The Bayes analysis set $\mathrm{K}$ values from 2 to 4 and examined the formation of colonies by group (Figure 5 ). The bar plot in Figure 5 confirms that the KGP and GOP populations showed different clusters from the other two Mongolian horse populations in all cases from the set $\mathrm{K}$ values. The remaining two populations showed similar patterns. The KGP and GOP populations were separated into different clusters when K3 and the KTP and USP populations were represented as a mixture with among. When the $\mathrm{K}$ value reached 4 , the KGP and GOP populations were still separated into dif-

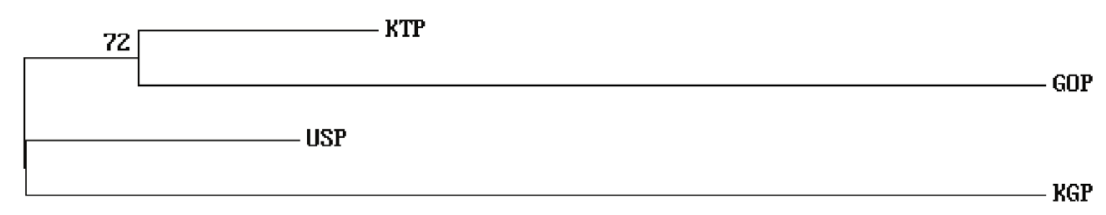

Figure 2. Neighbor-Joined tree showing the genetic distances among the four populations using Nei's DA genetic distance on the basis of allele frequencies from the $14 \mathrm{MS}$ loci. The number in the branch indicates the percentage of occurrence after 1,000 bootstrap replicates. MS, microsatellite; KTP, Khentii province; USP, Uvs province; GOP, Omnogovi and Dundgovi province; KGP, Khovsgol province. 
Principal Coordinates Analysis (PCoA)

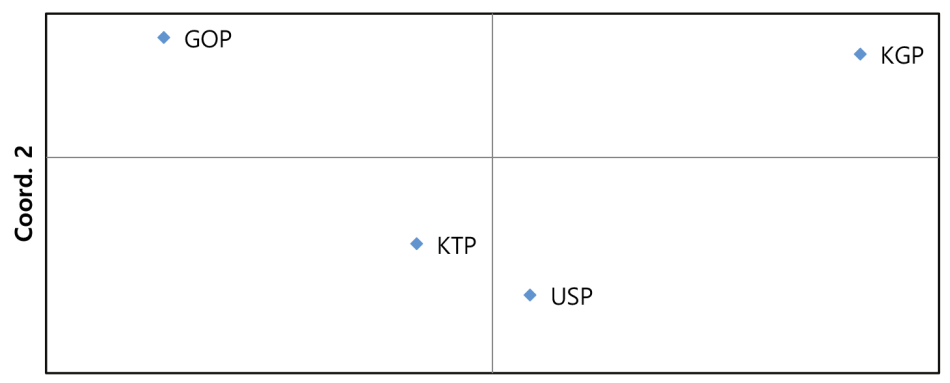

Coord. 1

Figure 3. Principal Coordinate Analysis of allele frequencies from the 14 MS loci genotypes in four populations using GenAIEx. MS, microsatellite; KTP, Khentii province; USP, Uvs province; GOP, Omnogovi and Dundgovi province; KGP, Khovsgol province.

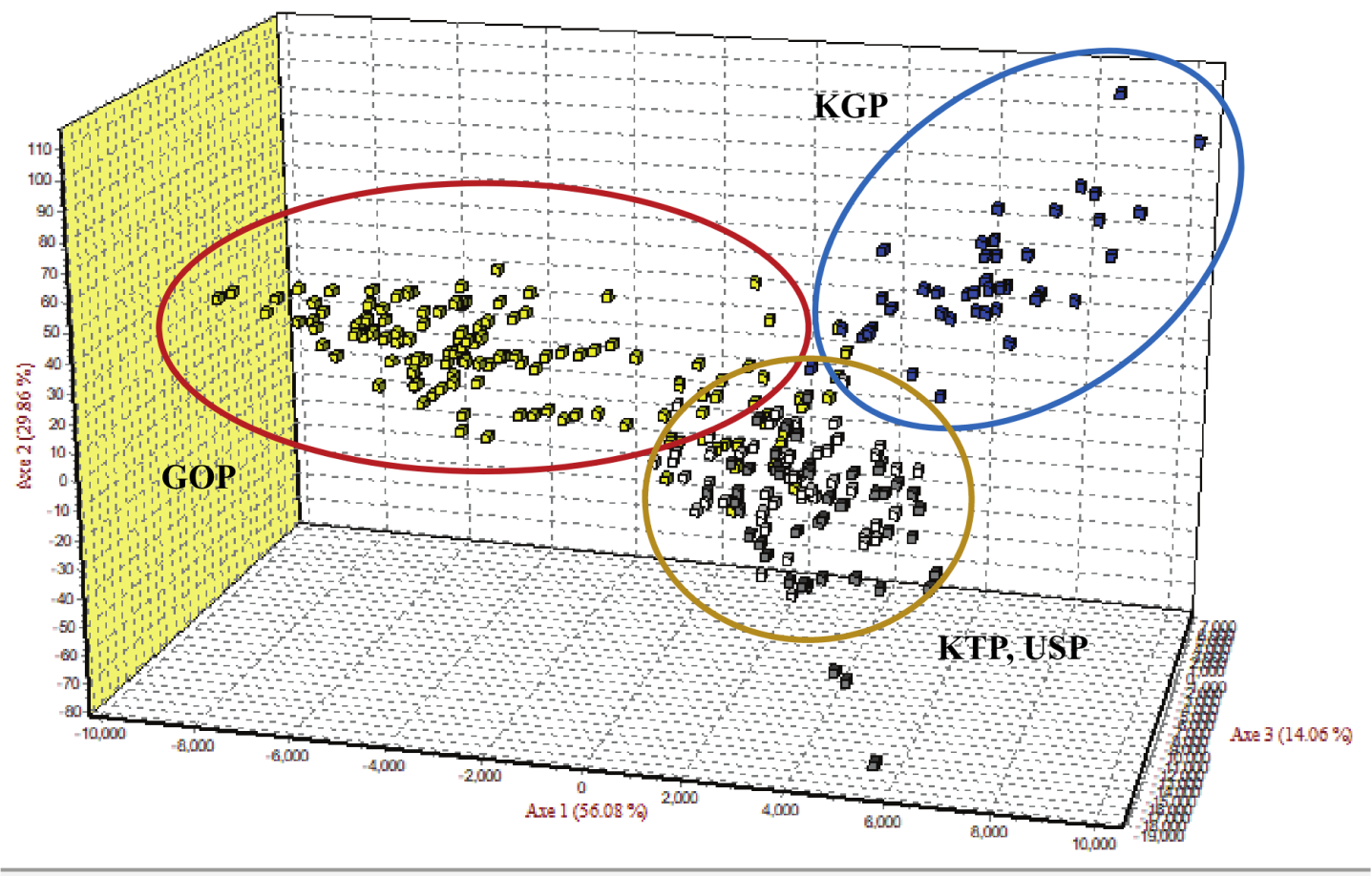

Figure 4. Factorial correspondence analysis of allele frequencies from the $14 \mathrm{MS}$ loci genotypes in four populations using Genetix. MS, microsatellite; KTP, Khentii province; USP, Uvs province; GOP, Omnogovi and Dundgovi province; KGP, Khovsgol province.

ferent clusters, but the KTP and USP populations primarily clustered with each other. Burn-in and MCMC repetitions (200,000 times and 1,000,000 times each, respectively) were used to estimate the optimal number of groups ( $\Delta \mathrm{K}$ values) when classifying groups between 2 and 4 , which were repeated 10 times by setting the $\mathrm{K}$ values from 2 to 4 , and the $\Delta \mathrm{K}$ value was estimated using a structure harvester. The highest $\Delta \mathrm{K}$ value $(1.375 \%)$ was obtained from $\mathrm{K}$ value 3 , which uses allele frequency data calculated with the $14 \mathrm{MS}$ markers and distinguishes the three groups when the group is divided (Supplementary Table S2). This indicates that it is the most appropriate method.

\section{DISCUSSION}

The purpose of this study was to verify the genetic diversity and correlation of Mongolian horses raised in five provinces using 14 MS markers. MS markers have been used to study the genetic diversity and population structure of horse breeds [23] and are commonly used in many countries for individual identification and parentage testing of horses.

The results of genetic variability, Nei's DA genetic distance, PCoA, FCA, and population structure provided genetic evidence for the differentiation of the population, and polymorphism was observed in all provinces. A total 

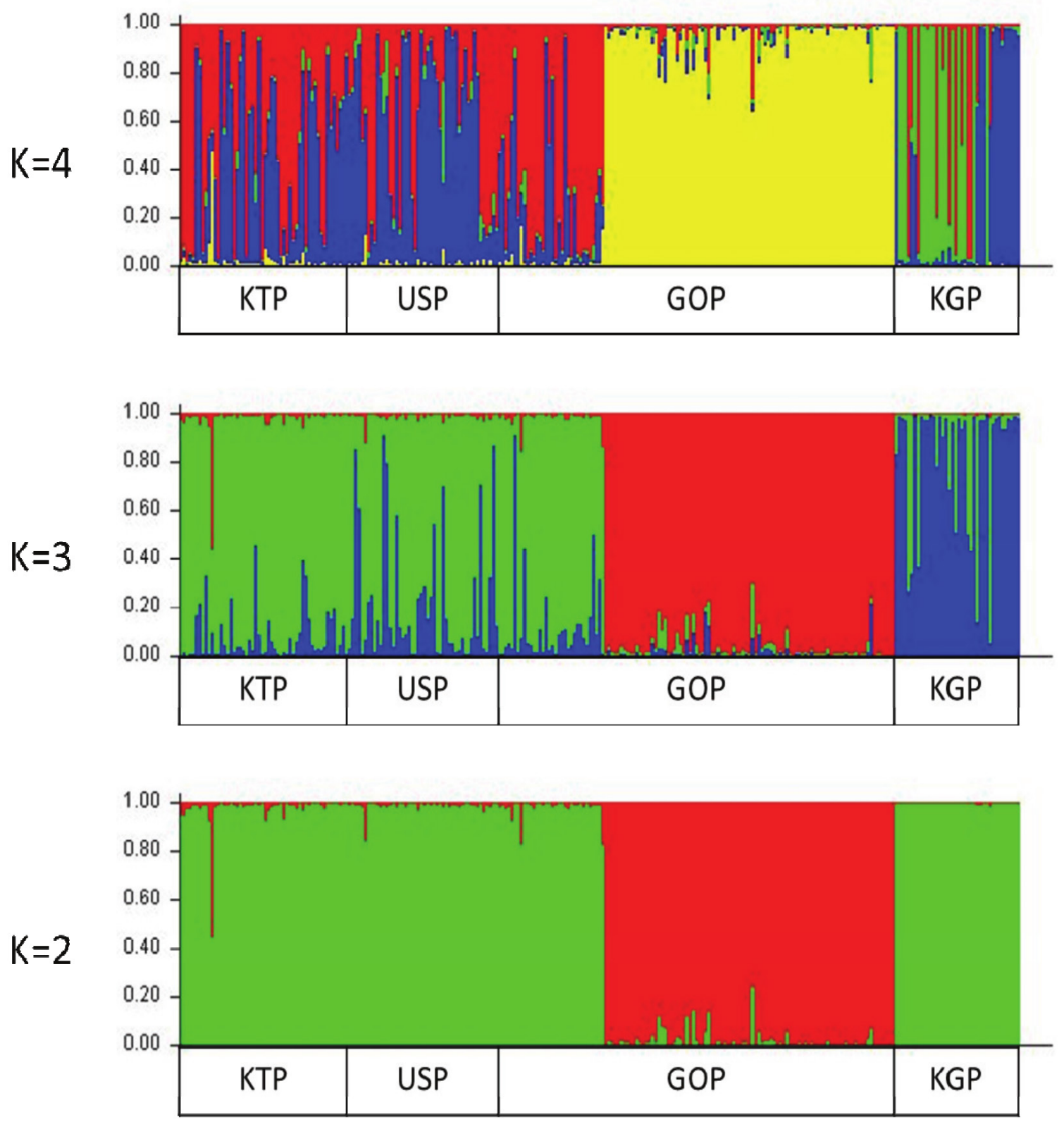

Figure 5. Structure analysis of the four horse populations. Cluster results from a structure analysis of 269 horses from four populations and based on 14 microsatellite (MS) markers. Each genotyped horse is represented by a single vertical line divided into $\mathrm{K}$ colors, where $\mathrm{K}$ is the number of clusters assumed in each structure analysis. Each vertical bar represents an individual horse. The colors on each vertical bar represent the probability of the individual belonging to each cluster.

of 160 alleles were detected in the 14 MS markers, the allele numbers ranged from 6 (HTG7) to 22 (ASB2), and the $\mathrm{H}_{\mathrm{Obs}}$ values ranged from 0.561 (HTG4) to 0.868 (ASB17). ASB17 showed the highest $\mathrm{H}_{\mathrm{Exp}}$ and PIC values of 0.885 and 0.866 , respectively, whereas HTG4 showed the lowest $\mathrm{H}_{\operatorname{Exp}}$ and PIC values of 0.572 and 0.535 , respectively.

Our estimate of genetic diversity $\left(\mathrm{H}_{\mathrm{Exp}}=0.772, \mathrm{H}_{\mathrm{Obs}}=0.757\right.$, and PIC $=0.737$ ) in the Mongolian horse populations was found to be similar to that reported by Cho [24] $\left(\mathrm{H}_{\mathrm{Exp}}=0.773\right.$, $\mathrm{H}_{\mathrm{Obs}}=0.696$, and $\mathrm{PIC}=0.742$ ). Tozaki et al [25] found that the average heterozygosity within each population of Mon- golian horses was between 0.75 and 0.77 . A higher value than our study was observed by Cho [26] $\left(\mathrm{H}_{\mathrm{Exp}}=0.809, \mathrm{H}_{\mathrm{Obs}}=\right.$ 0.833 , and $\mathrm{PIC}=0.761)$ and Dorji et al [27] $\left(\mathrm{H}_{\text {Exp }}=0.78\right.$, $\mathrm{H}_{\mathrm{Obs}}=0.79$, and $\left.\mathrm{PIC}=0.77\right)$. Lower values were reported by Giacomoni et al [23] $\left(\mathrm{H}_{\text {Exp }}=0.74, \mathrm{H}_{\mathrm{Obs}}=0.628\right.$, and $\mathrm{PIC}=$ 0.706). The average number of alleles in our study was 11.43 in the 14 MS loci. This is higher than that reported by Cho [26], in which the MNA of the Mongolian horse populations using $11 \mathrm{MS}$ loci was 8.18 alleles per locus. These MNA values were higher than the data published for other horse breeds and are similar to the study of Zuccaro et al [28], who ob- 
served an MNA of 10.09 alleles using 11 MS loci.

Nei's DA genetic distance analysis highlighted the presence of a clear genetic separation between each province. The KTP and USP populations were the closest $(\mathrm{DA}=0.0535)$, and the largest difference was calculated for the GOP and KGP populations $(\mathrm{DA}=0.1797)$. The same results were obtained for PCoA, FCA, and the population structure. The KTP and USP populations had the closest genetic distances. This is possibly because they were each intercrossed with each other. In contrast, KGP and GOP populations were genetically differentiated from other provinces and suggest that both populations do not lose specific alleles unique. The population structure results also confirmed that the KGP and GOP populations were separated into different clusters in all cases.

According to Seo et al [29] and Dierks et al [30], MS markers are highly polymorphic when the sum of $\mathrm{H}_{\mathrm{Exp}} \geq 0.6$ and PIC $\geq 0.5$. Therefore, the results of this study suggest that MS markers, except the HTG4 marker, can be used to aid the conservation, traceability, and improved abilities of the horse populations in Mongolia. Consequently, the Mongolian horses in this study showed a high level of genetic diversity. It is essential to secure genetic resources to analyze the genetic diversity of livestock and to identify their genetic relationships. While horses are economically important animals in Mongolia, only a few molecular genetic studies have been conducted on the genetic resources of Mongolian horses. Therefore, individual management of Mongolian horses based on genetic differences between them seems to be necessary. Finally, it is expected that this study can be used as basic data for the preservation and improvement of Mongolian horses and the establishment of breeds in the future.

\section{CONFLICT OF INTEREST}

We certify that there is no conflict of interest with any financial organization regarding the material discussed in the manuscript.

\section{FUNDING}

The authors received no financial support for this article.

\section{SUPPLEMENTARY MATERIAL}

Supplementary file is available from: https://doi.org/10.5713/ ab.21.0497

Supplementary Table S1. Nei's genetic distance (DA) values among the four Mongolian horse populations

Supplementary Table S2. The mean likelihoods of models and standard deviation, and Delta K value using the Evanno method

\section{REFERENCES}

1. National Statistics Office of Mongolia [Internet]. Total number of livestock as of 2020; 2020 [cited 2021 July 15]. Available from: http://www.1212.mn/stat.aspx?LIST_ID=976_L10_1

2. Mang L. Mongolian man and horse. Inner Mongolia Science and Technology Press; 2002. pp. 3-31.

3. Li JL, Shi Y, Fan C, Manglai DJ. mtDNA diversity and origin of chinese mongolian horses. Asian-Australas J Anim Sci 2008;21:1696-702. https://doi.org/10.5713/ajas.2008.80193

4. Aberle KS, Distl O. Domestication of the horse: results based on microsatellite and mitochondrial DNA markers. Arch Anim Breed 2004;47:517-35. https://doi.org/10.5194/aab-47517-2004

5. Rege JEO, Marshall K, Notenbaert A, Ojango JMK, Okeyo AM. Pro-poor animal improvement and breeding - what can science do? Livest Sci 2011;136:15-28. https://doi.org/ 10.1016/j.livsci.2010.09.003

6. Ellegren H, Johansson M, Sandberg K, Andersson L. Cloning of highly polymorphic microsatellites in the horse. Anim Genet 1992;23:133-42. https://doi.org/10.1111/j.1365-2052. 1992.tb00032.x

7. Marklund S, Ellegren H, Eriksson S, et al. Parentage testing and linkage analysis in the horse using a set of highly polymorphic microsatellites. Anim Genet 1994;25:19-23.

8. Zohary D. The mode of domestication of the founder crops of Southwest Asian agriculture. In: Harris DR, ed. The origin and spread of agriculture and pastoralism in Eurasia. London, UK: University College of London Press; 1996. pp. 142-58.

9. Wright T. Comparative genomics of Mongolian purebred and hybrid horses- conserving an important breed [Thesis]. Honors and Undergraduate Research, Texas A\&M University; 2013 [cited 2021 Aug 27]. Available from: http:// oaktrust.library.tamu.edu/bitstream/handle/1969.1/148882/ WRIGHT-THESIS-2013.pdf; sequence $=1$

10. Ganbold O, Lee SH, Seo D, et al. A review of population genetics research on domestic animals in Mongolia and recommendations for the improvements. J Anim Breed Genom 2018;2:9-20. https://doi.org/10.12972/jabng.2018 0016

11.Park SDE. Trypanotolerance in West African cattle and the population genetic effects of selection. [Ph.D. Thesis] Dublin, Ireland: Dublin University; 2001.

12.Peakall R, Smouse PE. GenAlEx 6.5: genetic analysis in Excel. Population genetic software for teaching and research-an update. Bioinformatics 2012;28:2537-9. https://doi.org/10. 1093/bioinformatics/bts460

13.Belkhir K, Borsa P, Chikhi L, et al. GENETIX 4.05, logiciel sous Windows TM pour la génétique des populations. Laboratoire Génome, Populations, Interactions, CNRS UMR 5000, 
Université de Montpellier II, Montpellier France; 2004 [cited 2021 Sep 2]. Available from: https://kimura.univ-montp2. fr/genetix/

14. Nei M, Tajima F, Tateno Y. Accuracy of estimated phylogenetic trees from molecular data. II. Gene frequency data. J Mol Evol 1983;19:153-70. https://doi.org/10.1007/BF02300753

15. Takezaki N, Nei M, Tamura K. POPTREE2: software for constructing population trees from allele frequency data and computing other population statistics with Windows interface. Mol Biol Evol 2010;27:747-52. https://doi.org/10. 1093/molbev/msp312

16. Saitou N, Nei M. The neighbor-joining method: a new method for reconstructing phylogenetic trees. Mol Biol Evol 1987;4:406-25. https://doi.org/10.1093/oxfordjournals. molbev.a040454

17. Ota T. DISPAN: genetic distance and phylogenetic analysis. University Park, PA, USA: Pennsylvania State University; 1993.

18. Pritchard JK, Stephens M, Donnelly P. Inference of population structure using multilocus genotype data. Genetics 2000; 155:945-59. https://doi.org/10.1093/genetics/155.2.945

19. Falush D, Stephens M, Pritchard JK. Inference of population structure using multilocus genotype data: linked loci and correlated allele frequencies. Genetics 2003;164:1567-87. https://doi.org/10.1093/genetics/164.4.1567

20.Earl DA, vonHoldt BM. Structure harvester: a website and program for visualizing structure output and implementing the Evanno method. Conserv Genet Resour 2012;4:359-61. https://doi.org/10.1007/s12686-011-9548-7

21.Evanno G, Regnaut S, Goudet J. Detecting the number of clusters of individuals using the software STRUCTURE: a simulation study. Mol Ecol 2005;14:2611-20. https://doi.org/ 10.1111/j.1365-294X.2005.02553.x

22. Botstein D, White RL, Skolnick M, Davis RW. Construction of a genetic linkage map in man using restriction fragment length polymorphisms. Am J Hum Genet 1980;32:314-31.

23. Giacomoni EH, Fernández-Stolz GP, Freitas TRO. Genetic diversity in the Pantaneiro horse breed assessed using microsatellite DNA markers. Genet Mol Res 2008;7:261-70. https:// doi.org/10.4238/vol7-1gmr367

24. Cho GJ. Genetic relationship and characteristics using microsatellite DNA loci in horse breeds. J Life Sci 2007;17:699705. https://doi.org/10.5352/JLS.2007.17.5.699

25. Tozaki T, Takezaki N, Hasegawa T, et al. Microsatellite variation in Japanese and Asian horses and their phylogenetic relationship using a European horse outgroup. J Hered 2003;94:37480. https://doi.org/10.1093/jhered/esg079

26. Cho GJ. Genetic relationship among the Korean native and alien horses estimated by microsatellite polymorphism. AsianAustralas J Anim Sci 2006;19:784-8. https://doi.org/10.5713/ ajas. 2006.784

27.Dorji J, Tamang S, Tshewang T, Dorji T, Dorji TY. Genetic diversity and population structure of three traditional horse breeds of Bhutan based on 29 DNA microsatellite markers. PLoS One 2018:13:e0199376. https://doi.org/10.1371/journal. pone. 0199376

28.Zuccaro A, Bordonaro S, Criscione A, et al. Genetic diversity and admixture analysis of Sanfratellano and three other Italian horse breeds assessed by microsatellite markers. Animal 2008;2:991-8. https://doi.org/10.1017/S1751731108002255

29. Seo D, Bhuiyan MS, Sultana H, Heo JM, Lee JH. Genetic diversity analysis of South and East Asian duck populations using highly polymorphic microsatellite markers. AsianAustralas J Anim Sci 2016;29:471-8. https://doi.org/10.5713/ ajas.15.0915

30. Dierks C, Mömke S, Drögemüller C, Leeb T, Chowdhary BP, Distl O. A high-resolution comparative radiation hybrid map of equine chromosome 4q12-q22. Anim Genet 2006;37: 513-7. https://doi.org/10.1111/j.1365-2052.2006.01510.x 